UDK: 316:32(460:497.11)

DOI: https://doi.org/10.18485/legado_hispanico.2020.ch23

\author{
José-Miguel Palacios ${ }^{1}$ \\ Profesor Visitante, Colegio de Europa (Brujas) \\ Bélgica
}

\title{
EL NOVENTA Y OCHO ESPAÑOL Y EL NOVENTA Y OCHO SERBIO
}

Resumen

En noviembre de 1998 la Embajada de España en Belgrado, en colaboración con la Facultad de Filosofía, organizó una jornada académica para conmemorar el desastre de 1898. Además de rememorar el hecho histórico, se pretendía también lanzar un mensaje optimista a una Yugoslavia que estaba aproximándose a las últimas fases de su desintegración. Se trataba, en esencia, de utilizar el «modelo español» como ejemplo positivo, en línea con lo que se había hecho en otros países ex comunistas en el comienzo de sus transiciones. El muy escaso eco de la iniciativa arroja luz sobre la dificultad de utilizar modelos ajenos para orientar la evolución política de otros países. Veinte años más tarde, los países occidentales son ahora más conscientes de que los cambios auténticos y durables solo pueden proceder del interior de las sociedades afectadas o, al menos, deben ser asumidos por ellas. Se habla, pues, de «cooperación», más que de «ayuda», y se procuran evitar actitudes paternalistas.

Palabras clave: Desastre del 98, modelo español, transición, antigua Yugoslavia, poscomunismo.

\footnotetext{
${ }_{1}^{1}$ palacios.jm@outlook.com
} 


\section{España y Yugoslavia ${ }^{2}$}

España y los pueblos de la antigua Yugoslavia han tenido escasos contactos a lo largo de la historia ${ }^{3}$. Hasta el siglo XX apenas puede hablarse de las relaciones comerciales y consulares entre la república de Ragusa y la corona de Aragón, de algunas comunidades de judíos sefardíes, que encontraron refugio en el Imperio otomano tras ser expulsados de España y Portugal $^{4}$, del trabajo en España de ingenieros dálmatas ${ }^{5}$, y de poco más. En épocas más recientes, se puede mencionar la intervención del rey Alfonso XIII en favor de dieciséis serbios de Banja Luka, condenados a muerte en 1916 en el llamado Veleizdajnički proces ${ }^{6}$, pero, sobre todo, la presencia de voluntarios comunistas yugoslavos durante la Guerra Civil en las filas del Ejército Popular de la República (los španski borci) ${ }^{7}$. España no fue un destino importante de la emigración política yugoslava durante el titoísmo, de la misma manera que Yugoslavia no lo fue de la española durante el franquismo ${ }^{8}$. Y siendo ambos países hasta épocas muy recientes más emisores que receptores de emigración, no hubo en

\footnotetext{
${ }^{2}$ A lo largo del texto, se utilizará Yugoslavia (yugoslavo) en un doble sentido: en referencia a la República Socialista Federativa de Yugoslavia (hasta 1991), y a la República Federal de Yugoslavia (desde 1992).

${ }^{3}$ Aunque, desde luego, han existido. Francisco Veiga nos ha ofrecido una visión detallada de estos contactos a partir de 1850 (Veiga 2003a).

${ }^{4}$ El escritor sarajevita Eliezer Papo, en un divertido texto („Zapamćeni jezik“) publicado originalmente en el número 90 de Dani (7 diciembre 1998), cuenta cómo en el periodo de entreguerras una mujer sefardí oyó hablar en espańol moderno a un sacerdote que salía del consulado y, asombrada, le dijo a una amiga suya: «Viste, Blanka, pop đudijo?» («¿Viste, Blanca, que el cura es judío?»). Una anécdota que nos habla del completo aislamiento que existió durante siglos entre las comunidades sefardíes y la España contemporánea. Las bellas palabras sobre la patria perdida que Ivo Andrić pone en labios del judío sefardí Salomon Atijas al final de la Travnička hronika son una reconstrucción tardía de algo que quizá no sucediera.

${ }^{5}$ Durante el reinado de Carlos III, el ingeniero militar raguseo Mateo Vodopich (Mato Vodopić) construyó gran parte de los más destacados edificios militares y civiles de Cartagena. Fue autor, además, del proyecto de urbanización de la nueva ciudad de Águilas, al sur de la región de Murcia.

${ }^{6}$ Una calle del centro de Banja Luka lleva el nombre del Rey Alfonso.

${ }^{7}$ A pesar de los años transcurridos y de los importantes cambios políticos, sigue habiendo vías públicas dedicadas a los španski borci en ciudades como Belgrado, Niš, Podgorica, Ljubljana, Pula o Rovinj. En Ljubljana, uno de los centros culturales más importantes de la ciudad se llama Španski borci.

${ }^{8}$ Aunque Ante Pavelić, tras exiliarse a la Argentina, acabó encontrando refugio en la España de Franco, donde murió en 1959.
} 
ellos colonias importantes de inmigrantes económicos extranjeros. A esto hay que añadir la ausencia de relaciones diplomáticas entre 1941 y 1977 y unos intercambios comerciales cuyo volumen puede calificarse de insignificante ${ }^{9}$.

A pesar del escaso conocimiento mutuo, yugoslavos y españoles pueden haber tenido la impresión de que existían muchos elementos comunes entre ambos países: regímenes autoritarios, sangrientas guerras civiles, orgullo individual y colectivo, manifestado en el carácter indomable de guerrilleros y partisanos. Y también, por supuesto, la pasión por el deporte, sobre todo el fútbol y el baloncesto ${ }^{10}$. Así que el yugoslavo que leía a principios de los años ochenta que «entre 1960 y 1974, España pasó de ser un país agrícola atrasado a uno de los principales países industrializados» (Inđić 1982: 193) podía pensar que la evolución de su propio país no había sido muy distinta. Y cuando en los años ochenta diplomáticos y académicos españoles se encontraban con colegas yugoslavos, recibían a menudo la impresión de que los dos países se habían encontrado en un nivel similar de desarrollo, pero que España había sabido aprovechar sus oportunidades tras la muerte de Franco, mientras que Yugoslavia había desperdiciado las suyas. Una impresión que, según las estadísticas económicas, estaba basada en datos inexactos: el PIB per capita de Yugoslavia nunca llegó al 80\% del español y era apenas el 58\% en el momento de la muerte de Franco, en $1975^{11}$.

España era un país que los yugoslavos conocían mal, pero del que a menudo tenían una buena opinión. Según un estudio sociológico

\footnotetext{
${ }^{9}$ Jaime González-Torres, Consejero Económico y Comercial de la Embajada de España en Belgrado durante los años noventa. Correo electrónico personal al autor, 07.09.2019. Según datos oficiales yugoslavos, tanto las importaciones como las exportaciones de España suponían en 1983 y 1984 entre el 1\% y el 2\% de las procedentes / destinadas a los diez países de la CEE.

${ }^{10}$ Durante los años setenta y ochenta del siglo XX, la rivalidad deportiva contribuyó de una manera muy importante a configurar la imagen que en España se tenía de Yugoslavia. Las reiteradas derrotas del Real Madrid ante la Cibona de Zagreb, debidas sobre todo al genio de Dražen Petrović, fueron, probablemente, la causa de que en la semifinal del Mundial de baloncesto de 1986, que se celebró en España, el público local apoyara claramente al equipo soviético, algo nada frecuente en países occidentales por aquellos años. Uno de los jugadores yugoslavos, el croata Franjo Arapović, «sugirió que el público merecía que los tanques soviéticos invadieran Madrid». Según El País, «El apoyo de la afición a la URSS protagonizó la mejor jornada», 19.08.1986. Los lazos baloncestísticos entre los dos países tuvieron un epílogo inesperado cuando, tras el comienzo de las guerras yugoslavas, el Partizan de Belgrado jugó en Fuenlabrada como local la Euroliga 1991-92, que acabaría ganando.

${ }^{11}$ Según datos del Maddison Project.
} 
italoserbio realizado en Voivodina a mediados de los años noventa (Branković 1995: 63-64), los españoles recibían una valoración muy positiva (2,56 sobre un máximo de 3 puntos), solo por detrás de montenegrinos, rusos y judíos, pero claramente por delante de todos los pueblos vecinos o de otros, como alemanes $(2,03)$ y austriacos $(2,12)$, con los que las relaciones históricas y económicas de los pueblos yugoslavos habían sido mucho más intensas. Aunque hacia el final de la década de los noventa la opinión que bastantes serbios tenían sobre España se vio afectada negativamente por el posicionamiento político de algunos destacados políticos españoles ${ }^{12}$, puede que a pesar de todo hayan mantenido una actitud relativamente favorable hacia España. El propio Milošević, en su discurso ante el IV Congreso del Partido Socialista de Serbia (17 de febrero de 2000), destacaba a Espańa, junto con Francia e Italia, entre los países que podrían ser las siguientes víctimas de lo que él veía como un «nuevo fascismo» decidido a aplastar a los que se atrevían a desafiar sus directivas ${ }^{13}$.

Algo similar parece haber ocurrido también en sentido inverso y al comienzo de las guerras yugoslavas bastantes españoles probablemente pensaban que tenían mucho en común con los pueblos de la antigua Yugoslavia. Así, en el manual que el Ejército espańol distribuyó a los primeros contingentes enviados a Bosnia-Hercegovina, se decía que «los yugoslavos son generosos y sociables», que «la población civil es amistosa y abierta» y que el carácter de los bosnios es «parecido al español» ${ }^{14}$. A partir del comienzo de la desintegración y de las guerras, esta imagen colectiva «de los yugoslavos» se fragmentaría rápidamente en diferentes imágenes nacionales, cada una de las cuales se vería influida por la responsabilidad que, según la opinión occidental, le correspondía en el desencadenamiento de la tragedia. Como en el resto de Europa, la imagen colectiva de los serbios fue la más perjudicada.

\footnotetext{
${ }^{12}$ María del Mar Campos, que a finales de los años noventa fue lectora en Belgrado y Novi Sad, recuerda que «la primera vez que cruzamos la frontera en coche para entrar en Serbia los policías del servicio de aduanas decían 'España, ah Julio Iglesias, Barça, Real Madrid'. Cuando salimos, tras iniciarse el bombardeo, nos dijeron 'España, ah, Javier Solana'». Correo electrónico al autor, 10.09.2019.

${ }^{13}$ «Danas je na redu Srbija, ali, posle će doći Španija i Francuska, Italija... I čitava Evropa, naravno, ma koliko nekada bila moćna, a sada lojalna» (Antonić 2001: 163).

14 «'Un carácter parecido al español'. Un manual del Ejército explica a los legionarios qué se encontrarán en Bosnia-Herzegovina». El País, 02.11.1992.
} 


\section{El uso político del llamado «modelo español»}

Cuenta Adam Michnik que en 1989 había leído una entrevista con Felipe González en la que el Presidente del Gobierno español, «interrogado sobre el modelo español de transición democrática, respondió con asombro: "Ese tal modelo no existe".» (Michnik 2003). Sin embargo, durante los años que siguieron a la caída del muro de Berlín, ese inexistente modelo fue utilizado con frecuencia por el gobierno y la oposición españoles en sus intentos de ejercer alguna influencia sobre los procesos de cambio que se estaban desarrollando en Europa Central, Europa Oriental y los Balcanes ${ }^{15}$. Como señalan dos conocidos historiadores barceloneses (Veiga \& Ucelay da Cal 1997: 78),

el viejo juego de imágenes tópicas sobre Espańa ayudaron a reforzar la admiración por la transición española», ya que «concebido como un país cruel y de sangre caliente, dado a las revueltas y revoluciones, la sorpresa que generó una transición sin guerra civil bastó para que naciese el 'modelo español', con un rey simpático al frente y un futuro asegurado.

De manera que los políticos españoles de la época no se resistieron a la tentación de incorporar a su capital político el inesperado éxito de la transformación democrática española, un éxito en el que muchos de ellos habían tenido una participación directa.

En los años setenta, existía en toda la Europa comunista «una cierta esperanza [...] de que España [...] terminara por convertirse en un miembro más del bloque del Este» (Veiga 2003b) o, al menos, en un país no alineado. En la década siguiente, cuando los regímenes socialistas entran en crisis, se populariza la idea de una posible convergencia entre los dos sistemas. Precisamente en eso consistía el programa político y económico de la perestroika soviética, una vez agotado el impulso inicial regeneracionista. Por eso, durante los ańos setenta y hasta el final de los ochenta no se aprecia ni en Yugoslavia ni en los demás países de lo que entonces se llamaba «el Este» ningún interés especial por la posible aplicación de las lecciones de la transición espańola a la reforma de sus propios sistemas. En el caso particular de Yugoslavia, Jovan Mirić veía en 1985 la salida de la kriza precisamente dentro del sistem, recuperando sus esencias, un enfoque que, salvando las distancias, podría calificarse de «gorbachoviano». Y,

\footnotetext{
15 El ejemplo más destacado de utilización política del llamado «modelo español» lo constituyeron los Cursos de Verano sobre transición española organizados por la Universidad Complutense en Moscú en julio de 1991 (Bonet \& Cembrero 1991). En ellos participó el Presidente del Gobierno Felipe González, así como destacados miembros del Partido Socialista y de partidos de la oposición.
} 
Zoran Đinđić, que mostraba tener una comprensión muy sofisticada de la crisis que vivía el país (y su sistema) no veía otra solución para superarla que construir un modelo específico yugoslavo: «En Yugoslavia no puede incorporarse al orden del día la democratización, sino solo la creación de los requisitos previos para ella. Como consecuencia de este proceso, en unos cuantos decenios surgiría una sociedad civil. Por supuesto, con todas las particularidades que recibiría como consecuencia del marco en el que surge. Su carácter paradójico sería visible en su propio nombre, ya que sería una sociedad civil socialista» (Đinđić 1988: 64).

A partir de 1989 sí hubo cierto interés por el modelo español en algunos de los países que hasta entonces habían compuesto la Europa socialista, pero Yugoslavia ( $\mathrm{y}$, posteriormente, los estados sucesores) no estuvo (estuvieron) entre ellos. Tras el vértigo de los primeros ańos noventa, en los que las reflexiones sobre nación y estado desplazan en la mayor parte de la antigua Yugoslavia a las preocupaciones por el régimen y su democratización, la situación empezó a cambiar hacia mediados de la década. No tanto en Croacia, donde «la prioridad para los dirigentes del país era asentar la independencia conseguida hacía poco, y completar su integridad territorial ${ }^{16}$. Ni tampoco en Bosnia-Hercegovina, donde la guerra y sus consecuencias fueron el centro del discurso político y de las reflexiones académicas. Sí, en cambio, en la República Federal de Yugoslavia, en la que durante la mayor parte de los ańos noventa son muy populares los estudios sobre la transición. Una transición, en cualquier caso, muy distinta de la espańola. Una transición más caracterizada por el punto de origen, el sistema socialista, que por el punto de destino, la democracia de estilo occidental (Vidojević 1997: 9). Una transición concebida como un «estado permanente», más que como un «tránsito entre dos estados». Una transición en la que los ejemplos que más se estudian son los de Polonia y otros países poscomunistas, no el español.

Fuera de algunos círculos de hispanistas, la atención que recibe en estos años el «modelo español» es escasa. Únicamente Srđan Darmanović, desde 2016 Ministro de Asuntos Exteriores de Montenegro, ha estudiado a fondo las transiciones del Este en comparación con las del Sur (España y Portugal), aunque durante la década de los noventa era mucho más conocido como político que como académico ${ }^{17}$. Los autores españoles

\footnotetext{
${ }^{16}$ Luis Felipe Fernández de la Peña, Embajador de España en Croacia entre 1993 y 1998, en mensaje electrónico al autor (13.09.2019). En una línea similar, el autor ha sostenido en un trabajo anterior que «cuando en el curso del proceso surge el problema estatal, su solución es [...] prioritaria sobre la democratización» (Palacios 2003: 308).

${ }^{17}$ Fue diputado por Montenegro en la Asamblea Federal entre 1992 y 1996. En 2002
} 
apenas son leídos, con excepción de Juan José Linz, al que muchos ex yugoslavos consideran norteamericano, y Oriol Pi-Sunyer (citado por Vesna Pusić y Zoran Đinđić), que había desarrollado su carrera fuera de España y había publicado, sobre todo, en inglés. Y, quizá como consecuencia de ello, las referencias directas a la transición española en la literatura politológica son casi inexistentes en aquellos años. La excepción más notable la constituye un artículo de Vesna Pusić, en el que la profesora croata defendía la idea de que tras el final del anterior régimen socialista (en su opinión, de carácter totalitario) se habían formado en Croacia y en Serbia regímenes de carácter autoritario, que podrían evolucionar hacia la democracia siguiendo el modelo de España y Portugal. Según Vesna Pusić, «los países del sudeste europeo en los años noventa se parecen a Portugal y España en los años setenta, antes de la transición a la democracia», por lo que el «modelo mediterráneo» de transición les podría ser aplicable. Un modelo que «a lo largo de la transición permitió mantener la continuidad de las instituciones y evitar largos debates políticos sobre el pasado» (Pusić 1997: 16).

En cualquier caso, este interesante artículo de Vesna Pusić tuvo escaso eco en Croacia y casi ninguno en la República Federal de Yugoslavia. En toda la región acabó extendiéndose el convencimiento de que los modelos, por interesantes que resultasen, eran difícilmente exportables. Como señalaría más tarde Srđan Vučetić (2004: 132), «the useful lessons that the South has to offer to the Southeast are minimal», a pesar de que admitía que en el caso espańol, el factor nacional, clave para los desarrollos políticos en la antigua Yugoslavia, había también representado un papel importante. Como señala el argentino Agustín Cosovschi, para cualquier científico social ex yugoslavo, «instalado durante los años noventa en un terreno atravesado por transformaciones violentas, el triunfalismo ingenuo de algunos autores occidentales era poco más que un material para la ironía» (Cosovschi 2016: 119). Y el «modelo español», al fin y al cabo, no era otra cosa que un ejemplo más de ese «triunfalismo ingenuo».

\section{La Embajada de España en Belgrado, durante las guerras de los años noventa}

El último Embajador español ante la República Socialista Federativa de Yugoslavia, José Manuel Allendesalazar Valdés, abandonó el país

defendió su tesis doctoral titulada Demokratske tranzicije u Južnoj i Istočnoj Evropi. En años recientes, varios de sus alumnos en la Facultad de Ciencias Políticas de Podgorica han escrito trabajos en los que trataban de la transición española. 
en mayo de 1992 y a lo largo de los años siguientes la representación diplomática española estaría encabezada por dos Encargados de Negocios, Francisco Pascual de la Parte y José Antonio Bordallo Huidobro. Solo tras los acuerdos de Dayton las relaciones empezaron a normalizarse. En febrero de 1996, Carlos Westendorp, último Ministro de Asuntos Exteriores de Felipe González, visitó oficialmente Belgrado, dentro de un circuito regional que también incluyó Zagreb y Sarajevo, y el 28 de junio de 1996 era nombrado por fin un nuevo Embajador, Joaquín Pérez Gómez.

Durante toda la larga crisis yugoslava, España intentó actuar en el marco de la posición común europea y occidental, pero, al mismo tiempo, procuró utilizar la percibida buena disposición hacia ella de los ex yugoslavos, así como la falta de conflictos históricos entre España y esos países, para ejercer lo que se quería que fuera una «influencia positiva» en favor de una solución pacífica y definitiva del conflicto ${ }^{18}$. Una doble línea con no pocos elementos contradictorios que en ocasiones resultaría difícil gestionar.

Losacuerdos de Dayton senegociaron en noviembre de 1995, durante la presidencia española de la UE. Y aunque fueron los norteamericanos, no los europeos, los protagonistas de estas negociaciones, el Presidente del Gobierno Felipe González fue quien representó a la UE en la ceremonia de firma de los Acuerdos, el 14 de diciembre de 1995. El mismo González tuvo un papel muy destacado en la evolución posterior de la República Federal de Yugoslavia cuando en diciembre de 1996 encabezó una misión de la OSCE para mediar en la crisis provocada por las irregularidades cometidas durante las elecciones locales serbias de noviembre de 1996. La intervención del ex presidente español, claramente favorable a la oposición, fue mal recibida por el entorno de Milošević, cuyas impresiones quedan bien reflejadas en un artículo publicado en el diario belgradense Politika:

Lamentablemente, su misión no contribuyó a la democratización ni tampoco a la confianza democrática. Tras sólo unas horas pasadas en Belgrado, Felipe González, como un 'speedy González', llegó a 'averiguar' sin más que la oposición había ganado los comicios locales en 22 ciudades serbias. El informe, con unos resultados previamente acordados, lo tenía

\footnotetext{
${ }^{18}$ Pueden encontrarse multitud de referencias a la actitud positiva de la población ex yugoslava (serbia, en particular) a la presencia española. Así, el Ministro de Defensa Suárez Pertierra comentaba en enero de 1996 el despliegue de fuerzas españolas en la Hercegovina serbia tras los acuerdos de Dayton: «La reacción de la población serbobosnia al aumento del despliegue español 'no puede ser mejor'. 'La relación es muy fluida y piden que instalemos un destacamento allí’». El País, 14.01.1996.
} 
ya preparado, de modo que su corta visita a Belgrado le sirvió únicamente para que los malinformados creyeran en la credibilidad del informe hecho por orden ${ }^{19}$.

Tras la crisis provocada por las elecciones locales de 1996, la etapa de relativa estabilidad que había conocido el régimen de Milošević terminó abruptamente. Coincidiendo con los meses de anarquía que se vivieron en Albania entre enero y agosto de 1997, el Ejército de Liberación de Kósovo (UÇK) intensificó sus acciones y comenzó a ser conocido por las opiniones públicas occidentales. En 1998 había ya en Kósovo una situación de guerra abierta entre el UÇK y las fuerzas de seguridad serbias y yugoslavas, lo que condujo a la práctica interrupción del proceso político que buscaba la normalización de la situación en dicha región. Según avanzaba el año, se iba viendo cada vez como más probable una intervención militar internacional que pusiera término a los enfrentamientos. Y existían pocas dudas de que el resultado de la intervención, si llegaba a producirse, sería la separación de Kósovo. Al menos, de hecho.

En esta época final de la crisis yugoslava, la posición oficial española estuvo claramente alineada con la de Estados Unidos y la OTAN. Influyó en ello, probablemente, el que dos españoles ocuparan cargos de especial responsabilidad en las estructuras euroatlánticas: Javier Solana, Secretario General de la OTAN desde diciembre de 1995, y Carlos Westendorp, Alto Representante para Bosnia-Hercegovina desde junio de 1997. Pero, sobre todo, influyó la decidida orientación atlantista de la política exterior española durante los gobiernos de José María Aznar (1996-2004). A escala local, el Embajador español en Belgrado, Joaquín Pérez Gómez, intentó sacar el máximo partido posible de la imagen relativamente amable que proyectaba España y utilizar este capital político para favorecer la distensión entre las partes y la búsqueda de una solución negociada. Y lo hizo en sus encuentros oficiales con diversos actores políticos yugoslavos, pero también concediendo a la prensa local un buen número de entrevistas, en las que solía destacar los aspectos positivos de la experiencia española (el «modelo español»), y sugería que los principios sobre los que estaba basado eran de validez universal, por lo que podrían ser utilizados con provecho en cualquier país. El consenso, la descentralización y la lucha contra el terrorismo fueron las ideas fuerza que el Embajador Pérez Gómez repitió a lo largo de esos meses cruciales.

\footnotetext{
19 Puede encontrarse una traducción española de este artículo («A que no sea una repetición de González»), realizada por Marija Minić, en el número 22 del boletín Traducciones de la Embajada de España en Belgrado (pp. 18-19). Ver https://es.scribd. com/document/24015516/Traducciones-22-1998 (acceso: 8 septiembre 2019).
} 
En abril de 1998, el Embajador decía a dos periodistas de Naša Borba (Marjanović y Bisenić 1998) que «la clave del éxito de la transición española, que hizo que la autoritaria, dictatorial y unipartidista España de Franco se convirtiese en un Estado democrático, pluripartidista y con una economía de mercado, estuvo en el consenso de todos los actores sociales relevantes en torno a los principales objetivos nacionales». Añadía, además, que «es necesario que se establezca un diálogo abierto y que se ponga fin al terrorismo. Sería muy conveniente que los dirigentes políticos albaneses condenen y se distancien de todas las acciones terroristas ${ }^{20}$. Por último, sobre la cuestión territorial decía que «en España tenemos una constitución democrática, aprobada por todo el pueblo. Cada una de las regiones tiene su 'pequeña constitución'. [...] Contra aquellos que se sirven de esos métodos el Gobierno lucha dentro de los marcos legales y con instrumentos políticos, respetando las libertades civiles». En otras entrevistas concedidas durante esos meses, Pérez Gómez reiteraba los mismos argumentos ${ }^{21}$.

En este contexto es en el que surge la idea de organizar una jornada académica en torno al centenario de 1898. En ella se hablaría del fin del imperio español, pero siempre en relación con el nacimiento de la España moderna, con lo que el mensaje que se transmitía parecía evidente: una experiencia tan traumática como una amputación territorial puede tener también aspectos positivos. El olvido, siempre relativo, del pasado ayuda a centrarse en el futuro. Y la desaparición de algunas de las circunstancias que condicionaban la acción del viejo estado pueden ayudar a que el nuevo se desarrolle sobre una base mucho más firme. Tal y como se veía en aquellos años de optimismo, cien años después del desastre España había sabido reinventarse y escribir una historia de éxito.

\footnotetext{
${ }^{20}$ Esta petición a los dirigentes albaneses kosovares de que condenaran el terrorismo y se distanciaran de él la repitió también en las entrevistas privadas que mantuvo con ellos. Por ejemplo, durante su visita a Ibrahim Rugova el 21 de mayo de 1998. La respuesta de Rugova fue que dudaba de la existencia del UÇK y que sospechaba que podría tratarse de un invento de las fuerzas de seguridad serbias.

${ }^{21}$ Por ejemplo, la de Dragana Šuvarević para Nedeljni Telegraf (17 junio 1998), en la que, además, explicaba por qué, en su opinión, el modelo español y la mediación española podrían ser de ayuda: «En cierto sentido España se podría comparar con Yugoslavia, habida cuenta que en ambas se hablan diferentes idiomas, que las dos han salido de regímenes autoritarios y que somos países mediterráneos. España está suficientemente cerca como para comprender el problema, al tiempo que no es un país vecino que tenga pasiones particulares o intereses históricos. Los destacados políticos españoles como el Sr. Westendorp o el Sr. González, están suficientemente familiarizados para llegar a comprender los problemas, pero no han tenido contactos políticos tan estrechos con este país que les imposibiliten ser objetivos en su trato».
} 
Ese era el ejemplo positivo que se quería ofrecer a los atribulados yugoslavos de finales del siglo XX. Naturalmente, la presencia española en el seminario tenía que ser minoritaria y sin ningún ánimo de protagonismo. Resultaba esencial que la mayor parte de los ponentes fueran yugoslavos, hombres y mujeres que desde el Belgrado de 1998 reflexionaran sobre la España de un siglo antes y que, con un poco de suerte, llegaran a conclusiones que pudieran generalizarse a su propio país, a sus propias circunstancias. Como veremos, el éxito fue solo parcial.

\section{La jornada sobre el 98}

La jornada tuvo lugar el 24 de noviembre de 1998, organizada por el Departamento de Historia de la Facultad de Filosofía y los principales responsables de la organización fueron los profesores Dragoljub R. Živojinović y Nikola Samardžić. Aunque la idea inicial había surgido en la Embajada, el desarrollo del programa estuvo casi por completo en manos de la Universidad. Algo que era, por diseño, imprescindible. La asistencia de público fue notable y la prensa se hizo amplio eco de la actividad, que es lo que las embajadas buscan siempre cuando colaboran en la organización de actos de este tipo. Resúmenes de las principales ponencias serían publicados más tarde en la revista Beohispánica ${ }^{22}$.

Parte de los ponentes eran hispanistas, bien familiarizados con la historia y la literatura espańola, mientras que otra parte eran especialistas en historia serbia o norteamericana, con una idea muy general sobre España, su pasado y su presente. Entre los ponentes no hubo politólogos ni otros especialistas habituados al análisis comparado.

La visión de los no hispanistas reflejó una incomprensión profunda del planteamiento inicial del seminario. Para ellos España y Yugoslavia eran dos casos completamente distintos y no había nada en el desastre de Cuba que pudiera servir de orientación a la República Federal de Yugoslavia en el desastre que venía desarrollándose desde 1991 y que culminaría en 1999. Así, el Profesor Živojinović, uno de cuyos principales centros de interés científico era, precisamente, la historia de Estados Unidos, centró toda su intervención en cuestiones de política interior norteamericana, que favorecieron el abandono de su tradicional aislacionismo en favor de una política exterior intervencionista (Pérez Gómez 1997-98: 97). Por su parte, Mihailo Vojvodić, un experto en historia de Serbia a finales del siglo

\footnotetext{
${ }^{22}$ De existencia efímera, se publicó en forma electrónica en 1997 y 1998. Posteriormente, se editaría una versión en papel (Anuario 1997-98), coordinada por Jelena Filipović, César L. Díez Plaza, Jasmina Nikolić y Alicia Jiménez Mantsiou.
} 
XIX y principios del siglo XX, se refirió al eco en Serbia de un conflicto que, en sus contornos básicos, equiparó a las luchas de liberación nacional de los pueblos colonizados: «en los círculos dirigentes y en la opinión pública serbia se siguió con atención desde principios de 1898 el empeoramiento de las relaciones entre España y América, en cuyo origen estaba la insistencia de los Estados Unidos en erigirse como protector del pueblo cubano, que se había sublevado contra el gobierno español» (Pérez Gómez 1997-98: 96).

Las intervenciones de los hispanistas estuvieron más centradas en la dimensión española de la crisis y en la influencia del desastre en la posterior regeneración del país. Así, para Nikola Samardžić,

la sociedad española de fin de siglo no pudo cambiar radicalmente, debido a que su desarrollo económico progresaba con suma lentitud. (...) La resaca de la derrota contra los EE.UU. y, en general, el pesimismo del fin del siglo fueron poco a poco desvaneciéndose. Aunque se quedó sin imperio, España conservó su influencia en el mundo hispanoamericano (Pérez Gómez 1997-98: 96).

\section{Por su parte, para Dalibor Soldatić,}

la preocupación principal de los escritores de la generación del 98, en el momento de afrontar la realidad de la nueva España que se vislumbra apenas después del desastre del imperio colonial, y que apenas habrá que definir en las circunstancias nuevas, es deslindar con precisión el carácter de la cultura nacional. (...) En relación a ese mundo moderno ellos tienen el deber de definir las características que les harán incorporarse al mundo como una nación también moderna (Pérez Gómez 1997-98: 100).

Se trataba, en efecto, de una redefinición radical del paradigma justificador de la existencia del propio estado, que se aborda cuando resulta evidente que la vieja idea de la justificación divina del poder ya no funcionaba. En cierta medida, era un problema similar al que estaba enfrentando la antigua Yugoslavia durante los años noventa, cuando las viejas fuentes de legitimación (bratstvo i jedinstvo, o soberanía de la clase trabajadora, por ejemplo) ya no resultaban mínimamente convincentes, aunque Soldatić no llegó a formular esta observación de manera explícita. Durante la discusión, sí estuvo muy cerca de hacerlo Trivo Inđić, otro de los hispanistas presentes, quien se atrevió a sugerir que algunos de los problemas españoles finiseculares tenían bastante que ver con los yugoslavos del momento. 
En su introducción a la jornada, el Embajador Pérez Gómez había abundado en referencias a la situación política de aquellos meses. Había destacado, en particular, detalles de la España de 1898 que parecían plenamente aplicables a la República Federal de Yugoslavia de un siglo después: que «la impresión del desastre fue tanto más viva cuanto que la guerra se había emprendido con alegre inconsciencia», que era enorme la desproporción de fuerzas entre España y Estados Unidos o que, junto a la voz de la España oficial, anonadada por el desastre, se apreció también la existencia de «otra España en busca de los valores nacionales auténticos» (Pérez Gómez 1997-98: 91). Todo ello era muy coherente con la insistencia de Pérez Gómez en utilizar ejemplos positivos de la historia contemporánea de España para convencer a las elites políticas e intelectuales yugoslavas de que, en su propio interés, les convenía asumir unos cambios que en Occidente se consideraban imprescindibles.

\section{A modo de conclusión}

El seminario sobre el centenario de la guerra hispanonorteamericana de 1898 (el «desastre») es un buen ejemplo de cómo durante los años noventa se enfocó en algunos países occidentales la cuestión de la asistencia a los países ex comunistas, que estaban inmersos en una difícil transición y, en el caso de la antigua Yugoslavia, en una serie de procesos de construcción nacional acompañados (en ocasiones, estimulados) por guerras civiles. La intención de ayudar era sincera y la metodología que se utilizaba, basada en la exportación al Este de conceptos y prácticas occidentales, parecía razonable. Según la interpretación predominante durante aquellos ańos, el final de la Guerra Fría había demostrado la superioridad del sistema occidental (democracias liberales con economías de mercado) sobre el antiguo sistema comunista, y había reducido a la irrelevancia todas las propuestas o hipótesis de convergencia que habían surgido en décadas anteriores. En los propios países poscomunistas eran a menudo los dirigentes políticos y otros líderes de opinión quienes reclamaban la occidentalización. El resultado no podía ser otro que el que hemos podido observar en el caso de la acción espańola en la antigua Yugoslavia: una actitud ciertamente paternalista por parte del actor occidental, una escasa adaptación a las circunstancias concretas del país al que se pretendía ayudar y, en última instancia, un cierto resentimiento en sectores de la población y entre las elites de este último. 
Quizá fuera Rusia el primer país donde este problema se manifestó, cuando resultó evidente que la occidentalización rápida de la «terapia de choque» no iba a traer de inmediato la prosperidad económica ni la restauración de la eficiencia del aparato estatal. En 1993, un comentario editorial publicado en primera página de un popular periódico ruso pedía enfáticamente a los occidentales que, si no querían darles dinero, no les dieran nada, pero que, sobre todo, no les dieran consejos. Por favor. Y en una línea similar, un destacado periodista de Sarajevo se quejaba en octubre de 1999 a un funcionario español de que la manera occidental de ayudarlos consistía en enviar a grupos de jóvenes consultores, que se suponía debían enseñarles a hacer su trabajo. «No somos tontos», decía por entonces aquel periodista de Sarajevo. «Simplemente, nos hemos quedado sin dinero».

La jornada sobre el 98 respondía a esta misma idea de intentar ayudar desde fuera, vendiendo ideas que habían tenido éxito en otras latitudes a alguien que, se suponía, no iba a ser capaz de desarrollarlas por sí mismo. Un enfoque tan bienintencionado como, probablemente, erróneo. Por más que la experiencia de toda la humanidad esté ahí, disponible para quien quiera y sepa aprovecharla, las soluciones concretas son difíciles de elaborar desde el exterior, sin un conocimiento profundo de las particularidades que existen en todos los pueblos y épocas. Por eso, las impuestas desde fuera no suelen funcionar.

Veinte años después de aquella «década prodigiosa» que tendría que haber sido testigo, según palabras del politólogo estadounidense Francis Fukuyama, del «fin de la historia», los países occidentales son ahora más conscientes de que los cambios auténticos y durables solo pueden proceder del interior de las sociedades afectadas o, al menos, deben ser asumidos por ellas. Hablamos de «cooperación», más que de «ayuda», y procuramos evitar actitudes paternalistas e imposiciones (aunque sean bienintencionadas). Es un enfoque, sin embargo, que hace veinte años era aún minoritario y que solo algunos expresaban en público. Por ejemplo, el General Tomé López, uno de los comandantes del contingente militar espańol en Bosnia-Hercegovina, que escribía en 1999:

En mi personal opinión, mientras haya tanto organismo autónomo o dependiente pululando a su libre albedrío o lo que es peor con unos intereses partidistas y subjetivos en favor de una determinada nación; en tanto en cuanto no se busque el exclusivo bien de la población de la antigua Yugoslavia y por el contrario se sigan buscando intereses partidistas en beneficio de una parte de esa población o lo que es peor 
de otras naciones, comunidades, etnias o religiones, nunca se logrará una auténtica y prolongada paz entre sus gentes. Por todo eso me pregunto: ¿no sería mejor, a estas alturas, dejarles completamente solos para tratar de que se organizaran a su aire y sobre todo con carácter definitivo y estable, en lugar de andar detrás de ellos tratando de inculcarles lo que deben y tienen que hacer en muchas ocasiones al margen de sus propios deseos, intenciones, forma de pensar y de ser, de su mentalidad y de sus tradiciones históricas y culturales? (Tomé López 1999: 51).

\section{REFERENCIAS BIBLIOGRÁFICAS}

Antonić 2001: Slobodan Antonić. „Poslednje greške i pad Slobodana Miloševića". Reč, 62/8: 159-205.

Bonet \& Cembrero 1991: Pilar Bonet \& Ignacio Cembrero. «La transición devora a sus protagonistas». El País, 09.07.1991. Web. 14/09/2019.

Branković 1995: Srbobran Branković. Serbia at War with itself. Belgrade: Sociološko Društvo Srbije.

Cosovschi 2016: Agustín Cosovschi. «Distancia crítica desde la periferia. Itinerarios del concepto de transición en la sociología de Serbia y Croacia durante los años noventa». Papeles de Trabajo, 10 (18): 99-122.

Đinđić 1988: Zoran Đinđić. Jugoslavija kao nedovršena država. Novi Sad: Književna Zajednica Novog Sada.

Inđić 1982: Trivo Inđić. Savremena Španija. Beograd: Nolit.

Marjanović \& Bisenić 1997: Vladan Marjanović \& Dragan Bisenić. „Konsenzus je magična reč. Hoakin Peres Gomes, ambasador Španije u Beogradu“. Nedeljna Naša Borba, 04-05.04.1997. Web. 21/06/2019.

Michnik 2003: Adam Michnik. «España, gran escuela para los polacos». El País, 29.09.2003. Web. 14/09/2019.

Mirić 1985: Jovan Mirić. Sistem i kriza. Zagreb: Cekade.

Palacios 2003: José-Miguel Palacios. Transición democrática postcomunista.

Democratización y estatalidad en la Unión Soviética y en Yugoslavia.

Madrid: UNED ediciones.

Pérez Gómez et al. 1997-98: Joaquín Pérez Gómez et al. «Seminario '1898: Fin del Imperio Español y comienzo de la España Moderna. Belgrado, Facultad de Filosofía e Historia. 24.11.98' - resúmenes de las ponencias presentadas y leídas». Beohispánica, Anuario 199798: 90-101. 
Pusić 1997: Vesna Pusić. „Mediteranski model na zalasku autoritarnih režima“. Erasmus - časopis za kulturu demokracije, 20: 2-18.

Šuvarević 1998: Dragana Šuvarević. «El gobierno español no apoya el sucesivo movimiento de las tropas de la OTAN en esta región». Nedeljni Telegraf, 17.06.1998. Según la versión de Traducciones, 22 (31.07.1998): 25-30. Web. 21/06/2019.

Tomé López 1999: José María Tomé López. Impresiones y vivencias de un militar español en Bosnia-Herzegovina: de nuevo en BosniaHerzegovina dos años después 1997-1998. Zaragoza: Departamento de Presidencia y Relaciones Institucionales.

Veiga 2003a: Francisco Veiga. «Entre la 'realpolitik' y el entusiasmo. Acción exterior española en el Sudeste Europeo 1900-2001». Balkania 1: 7-25.

Veiga 2003b: Francisco Veiga. «La transición española vista desde los Balcanes». Ponencia presentada en el Conferencia La transición española a la democracia - Španska tranzicija ka demokratiji. Sarajevo, 11-12.12.2003.

Veiga \& Ucelay da Cal Veiga 1997-98: Francisco Veiga \& Enrique Ucelay da Cal. «El modelo español: una lectura desde los Balcanes». Beohispánica, Anuario 1997-98: 82-86. [Se trata de una serie de dos artículos, escritos en agosto de 1991, y que originalmente se titulaban «Desfile de modelos» I y II].

Vidojević 1997: Zoran Vidojević. Tranzicija, restauracija i neototalitarizam. Beograd: Centar za Sociološka Istraživanja IDN.

Vučetić 2004: Srđan Vučetić. «From Southern to Southeastern Europe: Any Lessons for Democratization Theory?». Southeast European Politics, Vol. V, No. 2-3: 115-141. 


\section{THE SPANISH 1898 AND THE SERBIAN 1998}

\section{Summary}

In November 1998 the Embassy of Spain in Belgrade, in collaboration with the Faculty of Philosophy, organized a symposium to commemorate the disaster of 1898. In addition to recalling the historical event, it was also intended to send an optimistic message to a Yugoslavia that was approaching the last phases of its disintegration. In essence, it was about using the «Spanish model» as a positive example, in line with what had been done in other ex-communist countries at the beginning of their transitions. The slight echo of the initiative sheds light on the difficulty of using foreign models to guide the political evolution of other countries. Twenty years later, Western countries are now more aware that authentic and lasting changes can only come from within the affected societies or, at least, must be assumed by them. The emphasis is on cooperation, rather than on assistance, and significant efforts are made to avoid paternalistic attitudes.

Keywords: 1898 disaster, Spanish model, transition, former Yugoslavia, post-Communism. 